\title{
Hydrological simulation of extreme flood scenarios for operational flood management at the Middle Elbe river
}

\author{
M. Helms, J. Ihringer, and R. Mikovec \\ Institute for Water and River Basin Management, Karlsruhe Institute of Technology, Karlsruhe, Germany \\ Correspondence to: M. Helms (helms@kit.edu)
}

Received: 31 January 2012 - Revised: 31 July 2012 - Accepted: 4 November 2012 - Published: 11 December 2012

\begin{abstract}
Operational flood management at the Middle Elbe river requires comprehensive knowledge about the magnitude and characteristics of possible extreme flood events. Since these events are not sufficiently included in available historical records, an extended sample of extreme flood events was generated by hydrological scenario simulation. Present paper emphasises simulations in the German part of the catchment of the Middle Elbe river and introduces the stochastic-conceptual precipitation-runoff model which was developed for this task. After validation of this model and its coupling with the weather forecast model COSMO and hydraulic-numerical models, a set of 25 flood scenarios could be simulated and provided for a planning of flood protection measures. Analysis of simulated scenarios reveal that extreme flood events at the Mulde and Middle Elbe rivers may have a wide spectrum of characteristics and may considerably exceed the magnitude of past flood events (e.g., those of August 2002).
\end{abstract}

\section{Introduction}

Operational flood management at the Elbe river and in its basin (Fig. 1) requires comprehensive knowledge of hydrological processes under extreme conditions. However, extreme (and rare) flood events may have diverse spatial and temporal characteristics which are partly not included in available historical records. This fact became obvious during the flood of August 2002 with a specific superposition of extreme flood waves originating from different Elbe tributaries and with specific effects along the Elbe river itself (backwater, dike breaches, inundations). One of the most affected areas during this event was the reach of the Middle Elbe around the city of Dessau (Fig. 1) with a superposition of flood waves of the Elbe and Mulde rivers. With regard to specific characteristics of extreme flood events, reliable flood statistics for the design of flood protection measures can hardly be derived in this area, e.g. for the gauge of Aken (Fig. 1). Furthermore, this conventional hydrological practice is not sufficient here, since future flood events of similar or higher magnitude may have different characteristics and thus different requirements to flood management. Sound long-term planning of flood protection measures and preparation of operational flood management in concrete cases of extreme events rather require an extended sample with a larger number and greater diversity of possible characteristics of extreme events. To derive such an extended sample with extreme flood hydrographs in present study, scenarios with modified input and boundary conditions (as compared to those of observed events) were simulated using hydrological models. These hydrological simulations contributed to the joint research project "Operational flood management under large-scale extreme conditions, using the example of the Middle Elbe" (funded by the German Ministry of Education and Research) with further sub-projects on meteorological, hydraulic and geotechnical (dike monitoring) issues. A summary of advancements and coupling of tools as well as interdisciplinary derivation and evaluation of extreme flood scenarios performed in this joint research project can be found in Kron et al. (2010). Present paper emphasises the largescale hydrological simulation technique newly developed for the German part of the Elbe basin (see Sect. 2) and the hydrological simulation of selected extreme flood scenarios in the overall catchment of the Middle Elbe river (upstream of gauge Aken; see Sect. 3). In Sect. 4, conclusions regarding operational flood management at the Elbe river are drawn. 


\section{Development and application of large-scale hydrological simulation techniques}

In present study, hydrological simulation was used to downscale the impact of flood-relevant weather situations to flood situations at river reaches of interest, e.g., at the Middle Elbe. In the Czech basin part, hydrological simulation was performed by project partners of the Czech Hydrometeorological Institute and AquaLogic Consulting. Since the focus of present paper is put on hydrological simulation in the German basin part, only a brief summary of simulation techniques applied in the Czech basin part is given in Sect. 2.1. A more comprehensive documentation of the development and diagnosis of the simulation technique for the German basin part as well as results of the superposition of Czech and German simulations are given in Sect. 2.2. Finally, interfaces to meteorological and hydraulic models are considered in Sect. 2.3.

\subsection{Hydrological simulation in the Czech basin part}

In the Czech basin part, the modelling system AQUALOG, which is the base of the official Czech flood forecast system, was applied by the Czech Hydrometeorological Institute and AquaLogic Consulting. Only a brief summary of AQUALOG is given here. Further information may be found at AquaLogic (2012). Using spatially interpolated meteorological parameters, the conceptual modules SNOW-17 and Sacramento/SAC-SMA of the US National Weather Service were used to simulate snowmelt and runoff generation in a 6-h time step for sub-catchments of a size between 5 and $30 \mathrm{~km}^{2}$. For runoff concentration in meso-scale catchments, unit hydrograph was applied. Different modules of flood routing (translation-diffusion model, MuskingumCunge) were finally used to obtain simulated hydrographs at the Czech-German borderline. It is emphasised that operation of the large Czech reservoirs system was embedded into the flood-routing procedure. After calibration for the period 2000-2005, the modelling system was successfully applied to the extreme flood events of August 2002 and March/April 2006.

\subsection{Hydrological simulation in the German basin part}

Using a translation-diffusion model analogous to the flood forecast system ELBA for the German reach of the Elbe river, flood waves of the Czech basin part were routed to the case study area of the Middle Elbe river. In this area, they were superposed with flood waves originating from the intermediate catchment (IC) between the gauges of Dresden and Aken (see Fig. 1). For this IC, a large-scale and taskspecific stochastic-conceptual precipitation-runoff (SCPR) model was developed.

Distributed daily input of the IC was derived by interpolation of observed precipitation depths (inverse-distance

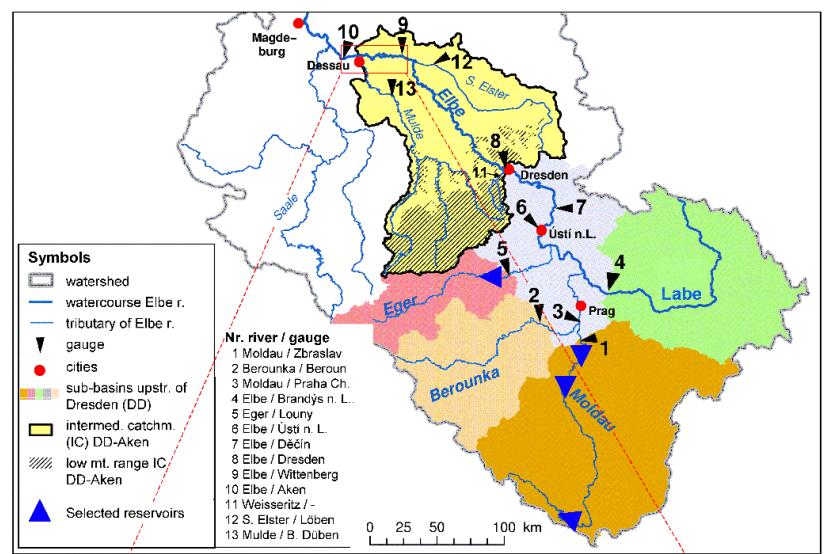

Case study area at the Middle Elbe river

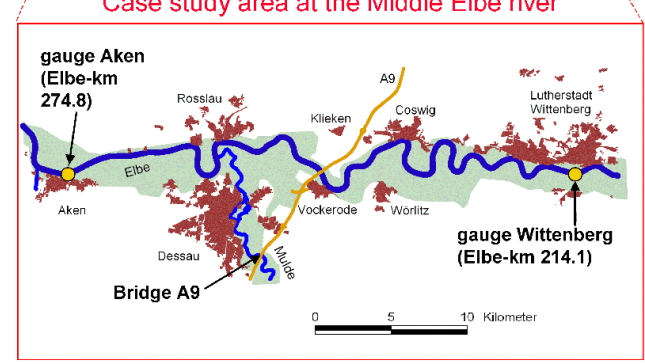

Fig. 1. Map of the Elbe basin upstream of the Elbe gauge Aken including the main Elbe tributaries and their catchments, selected gauges and the low mountain range in the intermediate catchment of the Elbe gauges Dresden and Aken. Detailed map in the lower part (provided by Kron et al., 2010) shows the reach of the Middle Elbe river which was chosen as case study area of the joint research project to which the work of present paper contributed.

method) and temperatures (modified nearest-neighbour method with altitude gradients) to a $5 \times 5 \mathrm{~km}$ grid. Subsequently, a snow-compaction model (Knauf, 1980) using interpolated meteorological parameters was run for each grid element.

The flow hydrograph of the IC (which is required for the diagnosis of the SCPR model, but cannot be observed directly) was estimated from observed flow series of Elbe and tributary gauges. In this procedure, the hydrograph of Dresden is first routed to Aken where it is subtracted from the observed hydrograph. Since the difference hydrograph has a significantly smaller magnitude than the overall hydrograph, a relatively high error of the difference hydrograph had to be taken into account. Therefore, a regression approach explaining the difference hydrograph by the tributary flow series of Bad Düben/Mulde and Löben/Schwarze Elster (both after routing to Aken) was developed (coefficient of determination 0.88 ). Daily flow series of the IC, which is the output of this system, was then estimated with the derived regression equation and is specified as "observed" flow series of the IC in present paper. 


\subsubsection{Development of a stochastic-conceptual precipitation-runoff (SCPR) model}

Using the derived daily input and output series of the IC in the period 1963-1996, the structure of the SCPR model was developed and calibrated. It is emphasised that the model structure was not à-priori given, thus avoiding problems of model transferability between different catchments, scale areas and topics. With respect to the given large-scale IC $\left(17000 \mathrm{~km}^{2}\right)$, topic (downscaling of meteorological input to extreme flood hydrographs at selected sites), data and (limited detailed) knowledge of processes, a parsimonious and thus robust model structure with well-identifiable parameters is suited. However, to account for the diversity of hydrological processes (including rare extreme events) in the development and calibration of a sufficiently versatile model structure, a long-term series ( $32 \mathrm{yr}$ ) is used.

To derive such a model structure, a top-down approach starting at the level of interest (flow hydrograph of the IC) was pursued. According to a principle of progressive modification, a simple but developable auxiliary model structure was adopted in a first step. It focuses on robust or long-term mean characteristics of the analysed system (IC). According to an analysis of selected recession curves, the flow series was separated into three components (inert base flow of a conceptual linear reservoir; base flow of a non-linear reservoir; quick flow). Large-scale runoff concentration in the IC was simulated using cascades of linear reservoirs. Runoff generation was initially represented by long-term mean gain factors (volume ratio of flow component to precipitation). For this auxiliary model structure, parameters were optimised and reasonable parameter ranges were narrowed down (for subsequent steps of model development where parameter values were updated within these ranges).

In a diagnosis of the simulated vs. the observed hydrograph, residuals of the auxiliary model were analysed and physically interpreted in order to identify appropriate modifications and extensions of the model structure. With the accordingly modified model structure, the procedure (simulation - diagnosis of residuals - modification of the model structure) was continued in several steps until no further modification for a significant improvement of the model could be identified. In addition to above mentioned components of the auxiliary model structure, robust seasonal variations of the gain factors were introduced in a second step. Using simulated output of the non-linear reservoir as time-variant hydrological state measure as well as (preferably weak) non-linear tuning functions to account for effects about which no detailed knowledge was derived, a final stage of a lumped model structure ("basic module" for the overall IC) was achieved in a third step. A scheme of this module with well-defined parameter values is shown in Fig. 2 (grey box). Inspite of its relatively simple structure, the basic module performs well in about $97.5 \%$ of daily time

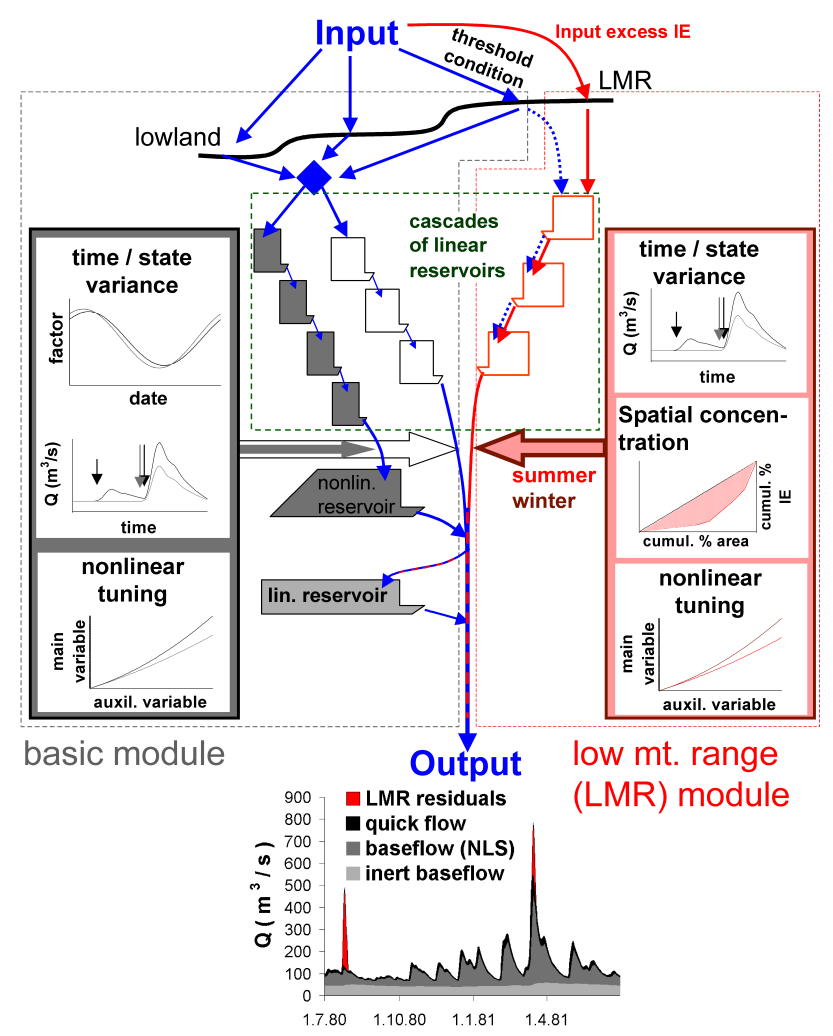

Fig. 2. Scheme of a stochastic-conceptual precipitation-runoff (SCPR) model developed for the intermediate catchment of the Elbe gauges Dresden and Aken.

steps 1963-1996 (Nash-Sutcliffe coefficient 0.81) and could be validated in a split-sample test.

Significant deficits of the basic module occurred, however, at 25 flood events with spatial concentration of input in the low mountain range of the IC (LMR; see Fig. 1). Furthermore, observed hydrographs of these flood events were characterized by sharp peaks which were underestimated by the basic module ("LMR residuals", see Fig. 2). The residual analysis identifying the sample of $25 \mathrm{PR}$ events also allowed the derivation of a comprehensive threshold condition of the excess of LMR input depth as compared to those of the overall IC.

To simulate the LMR residuals, a similar approach like for the basic module was pursued (progressive modification). In the first step, LMR residuals were simulated with an auxiliary model structure. In this model structure, daily input excess of the LMR (input depth of the LMR minus input depth of the overall IC) and the daily LMR input depth without the excess (as a major boundary condition) were both convoluted with the same cascade of linear reservoirs and then used in a linear regression approach to explain the LMR residuals. In further steps, a summer/winter differentiation and an antecedent precipitation index were introduced to account for seasonal and state-dependent effects. Furthermore, daily Gini coefficients 
of input excess values of above mentioned $5 \times 5 \mathrm{~km}$ grid elements were used to parameterise the effect of event-specific spatial concentration of input excess within the LMR area (identifiable only in the winter half year). Remaining effects about which no detailed knowledge was derived were again represented by non-linear tuning functions. At the final stage of the derived model structure ("LMR module", see Fig. 2, red box), a reasonably good fit to the LMR residuals could be achieved with well-defined parameter values (Nash-Sutcliffe coefficient 0.75 ). However, validation of the LMR module by means of a split-sample test was problematic regarding small split samples with heterogeneous flood events. Under simplified assumptions, at least a partial validation suceeded. Complete validation would require the extension of the (overall) sample to the period before 1963. However, it can be assumed that calibration of the overall sample is much more robust than those for small split samples. Furthermore, a main argument supporting the derived LMR module is its successful application to the extreme flood events 2002 and 2006 (see below).

Combining the basic module and the LMR module, the performance of the overall SCPR model in the period 1963-1996 is good (Nash-Sutcliffe coefficient 0.81; see also Fig. 3).

In order to analyse its (extrapolated) behaviour under extreme conditions, the SCPR model was applied without recalibration to the flood events of August 2002 and April 2006. "Observed" hydrographs of the IC for diagnosis were derived from flow series of tributary gauges (Bad Düben, Löben) using above described routing/regression approach. This approach excludes strong and event-specific retention and backwater effects along the Elbe river and lower reaches of the tributaries which cannot be captured in PR simulation. In Fig. 4, it can be seen that simulated hydrographs are higher than the observed ones. However, this diagnosis requires an interpretation. Using the routing/regression approach to estimate the hydrograph of the flood event of August 2002, underestimation occurs partly due to untypical spatial characteristics of the flood event, e.g., regarding the fact that the extreme flood volume of the Weisseritz river (see Fig. 1) was not explicitely taken into account due to missing flow data. Furthermore, numerous dike breaches and retention effects along the Mulde river upstream of Bad Düben occurred during the flood event of August 2002. In addition, strong retention effects of reservoirs in the catchment have to be taken into account for both flood events, August 2002 and April 2006. Known retention volumes are superposed to the flood peaks in Fig. 4. In summing up these effects, it is plausible that the hydrographs of the PR simulation are higher than the (incompletely) observed ones. In any case, the order of magnitude of the simulated hydrographs is correct, thus confirming the applicability of the SCPR model on extreme flood events and scenarios in the IC.

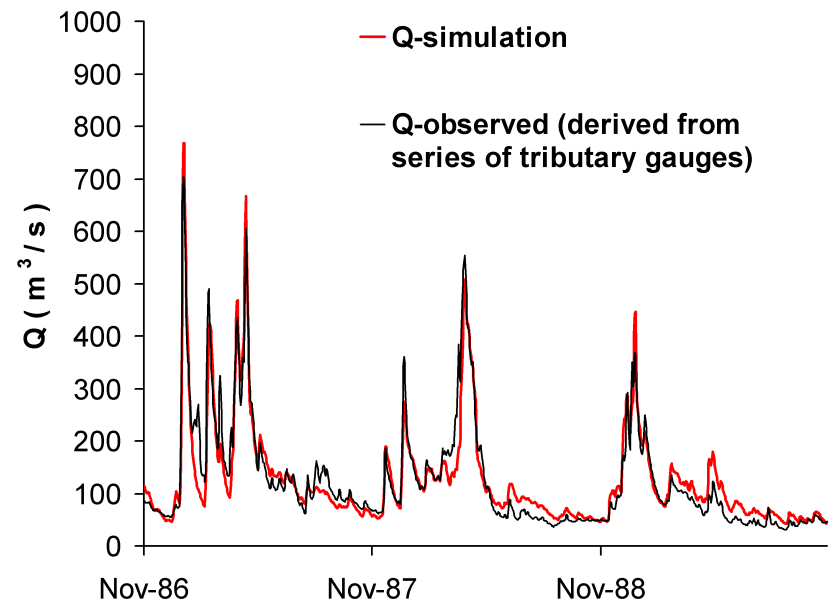

Fig. 3. Fit of daily flow simulation using the SCPR model to the observed flow series of the intermediate catchment of the Elbe gauges Dresden and Aken shown for a three-year period.

\subsubsection{Superposition of Czech and German simulation results}

Event-specific effects along the German part of the Elbe river during the flood event of August 2002 (due to dike breaches, retention and backwater effects) concerned also the routing of hydrographs from the Czech basin part. These effects complicated a coupling of Czech and German PR simulations as well as the diagnosis of the hydrological simulations in the overall basin. Corresponding to the estimation of the hydrograph of the IC from observed tributary flow series (see above), such event-specific effects were excluded from the routing. Altogether, a "basic scenario" with diked channels of unlimited flow capacity was assumed for the German part of the Elbe river and the lower reaches of its tributaries. Due to missing retention effects, hydrographs of the basic scenario have higher flood peaks than those of the real event: in Wittenberg $4200 \mathrm{~m}^{3} \mathrm{~s}^{-1}$ instead of $3990 \mathrm{~m}^{3} \mathrm{~s}^{-1}$ and in Aken $4480 \mathrm{~m}^{3} \mathrm{~s}^{-1}$ instead of $4180 \mathrm{~m}^{3} \mathrm{~s}^{-1}$ (Fig. 5). Hydrographs resulting from PR simulations and flow routing under the same conditions fit well to those obtained with observed upstream hydrographs (Fig. 5), thus confirming that PR simulation in the overall basin of the Middle Elbe river performs well. To ensure homogeneous routing conditions in diagnosis and evaluation of hydrological simulation results, conditions of the basic scenario were assumed in all other extreme flood events and scenarios considered in present paper.

\subsection{Interdisciplinary interfaces}

Simulation of extreme flood scenarios for operational flood management required the development of interfaces to the weather forecast model COSMO of the German Weather Service (DWD) as well as to hydraulic-numerical (HN) models in the case study area (Middle Elbe river). 

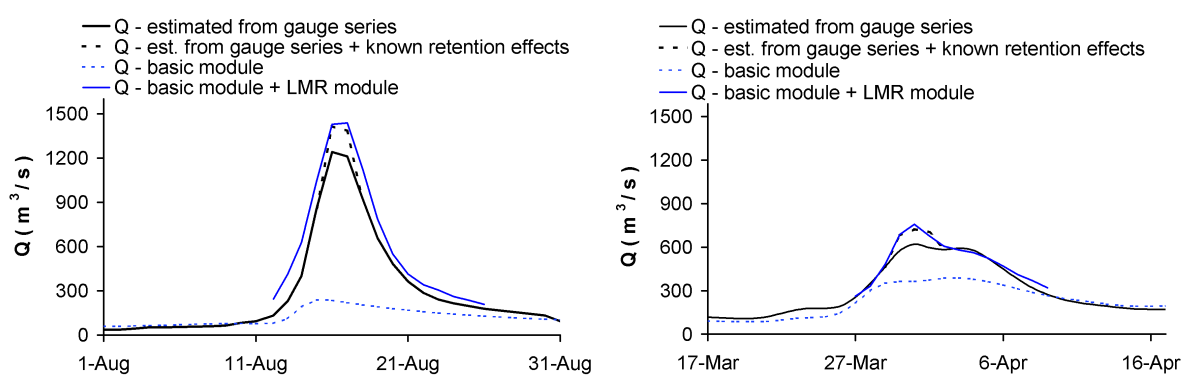

Fig. 4. Flow simulation of the flood events of August 2002 and March/April 2006 in the intermediate catchment of the Elbe gauges Dresden and Aken using the SCPR model. In comparison the hydrographs estimated from available gauged flow series are shown.

To couple hydrological and COSMO simulations, an areaproportional transformation of COSMO output grid values (spatial resolution $7 \mathrm{~km}$ ) to the (intersected) input grid values of the hydrological models was derived. COSMO simulation of the flood-inducing weather situation of 6-14 August 2002 was perfomed by meteorologists (Schlüter and Schädler, 2010). Subsequent hydrological modelling using the output of the COSMO simulation partly revealed deficits of simulated hydrographs at the scale of the major tributary catchments which are shown in Fig. 1. However, in aggregated tributaries, these deficits compensate more and more and may therefore be explained mainly by deficits in the spatio-temporal resolution of simulated precipitation. In Ustí n. L., the simulated hydrograph provided by the Czech partners fits the observed hydrograph well except at the rising limb (Fig. 5). In Aken, a very good fit of the simulated hydrograph (using COSMO, Aqualog, ELBA and the SCPR model) to those of the basic scenario was finally found. Applicability of the coupled modelling system and hence scenario-capability were thus confirmed at the scale range of the basin of the Middle Elbe river.

Furthermore, simulated hydrographs had to be provided at the upper boundaries of a $\mathrm{HN}$ model of the Middle Elbe river (bridge of the highway A9 over the Mulde river; gauge of Wittenberg at the Elbe river, see Fig. 1 and Oberle et al., 2008). To derive hydrographs of these sites from the lumped hydrograph of Aken, the simulated hydrograph of the IC Dresden-Aken was in a first step subdivided to a hydrograph originating from the Mulde catchment and to another from the remaining eastern part of the IC. Event-specific weighting factors proportional to the input volumina of the respective parts of the IC and LMR areas were used to subdivide the simulated flow components of the basic module and of the LMR module. Subsequently, the flow components of the basic and LMR modules were summed up for each of the two parts of the IC.

The transfer of the Mulde hydrograph from Aken to the A9 site was then performed using regression equations. These equations could be derived from data produced by flow routing experiments with a set of flood events with similar characteristics to those of the event of interest.
Furthermore, the hydrograph component at Aken originating from upstream of the Mulde inflow was transferred to Wittenberg. For this purpose, event-specific polynoms were used. These polynoms describe the relationship between the sum of the hydrograph of the eastern part of the IC and the hydrograph routed from Dresden to Aken (explained variable) and the hydrograph routed from Dresden to Aken alone (explaining variable). Polynoms were derived separately for the rising and falling limbs of the hydrograph. Unstable polynom behaviour in the area around the flood peak was avoided. Polynoms derived in Aken were then applied to the hydrograph routed from Dresden to Wittenberg in order to obtain the overall hydrograph of Wittenberg. Application of the described, rather empirical disaggregation and transfer concept was restricted to flood events and scenarios with compact shape or similar spatial distribution characteristics within the IC during the whole event.

After coupling of the validated hydrological models to COSMO and to HN models for the Middle Elbe and lower Mulde river, hydrological simulations of extreme flood scenarios could be carried out in an interdisciplinary context. This will be the topic of the following section.

\section{Hydrological simulation of extreme flood scenarios for the Middle Elbe river}

In consultation with the Czech and interdisciplinary project partners, a set of 25 extreme flood scenarios was defined and analysed. Based on past flood events (e.g., August 2002), scenarios with modified event characteristics were defined in three principle ways as described in the following sections. Present paper focuses on scenarios with most meaningful results for operational flood management. All scenarios are based on conditions of the basic scenario.

1. Gradual modification of hydrological and meteorological process variables: among the hydrological process variables, flood-inducing input and antecedent moisture conditions of major flood events were incrementally increased (e.g., by 10 and $20 \%$ ). These modifications, which are rather sensitivity studies regarding 


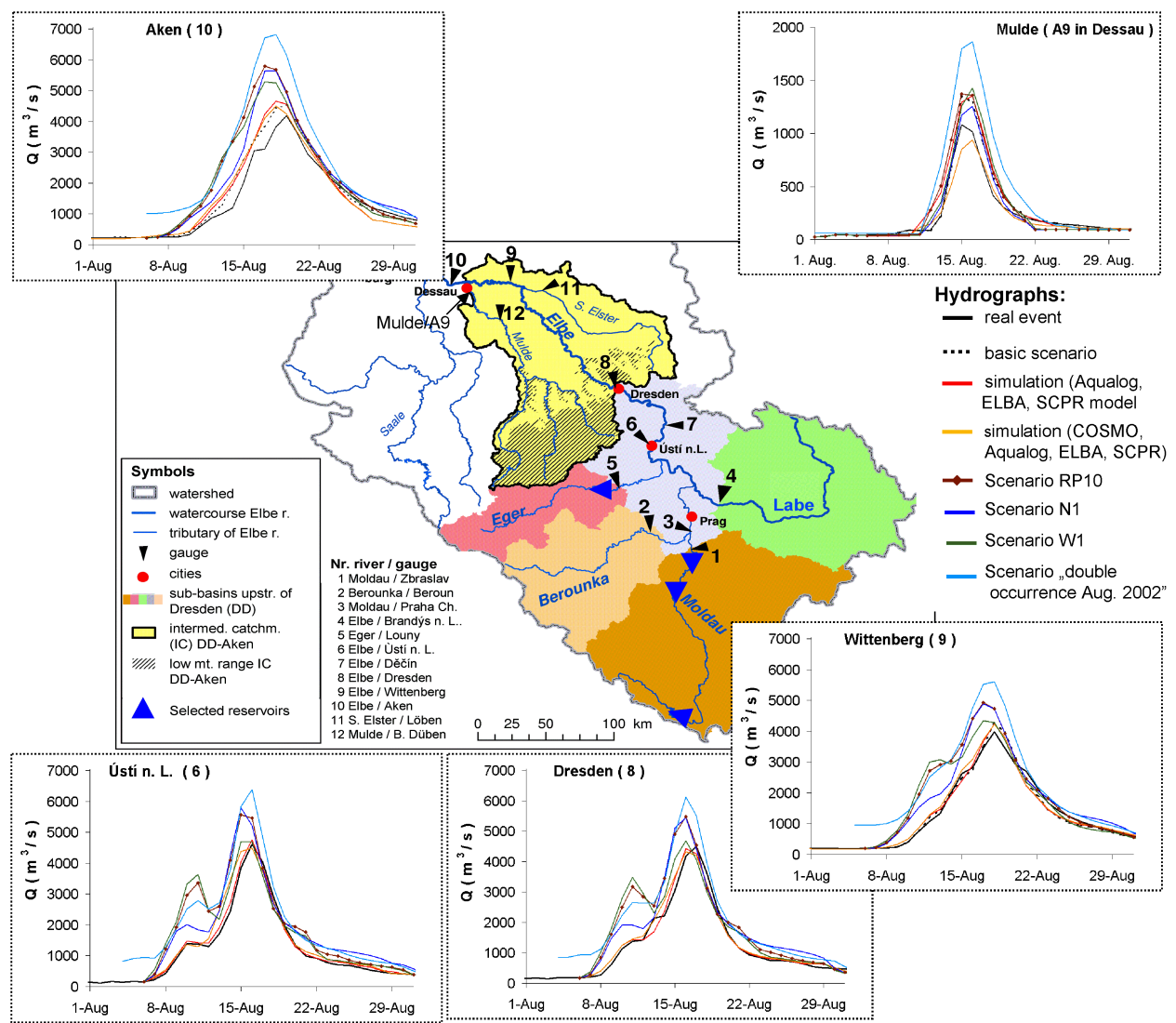

Fig. 5. Observed and simulated flood events of August 2002 in the Elbe basin upstream of Aken. As compared to the real event, scenarios with modified meteorological and hydrological conditions reveal a wide spectrum of possible event characteristics.

extrapolation characteristics of the hydrological models than well-founded scenarios, resulted in significant, but plausible increases of hydrographs.

Furthermore, air mass properties in the boundary and initial fields of COSMO, as applied to the flood event of August 2002, were varied by meteorologists. Relative humidity was increased and decreased by 5,10 , 15 and $20 \%$ while temperature was kept constant, and temperature was increased and decreased by $0.5,1$, 1.5 and $2 \mathrm{~K}$ while relative humidity was kept constant (Schlüter and Schädler, 2010). Compared to the basic scenario, particularly the scenario with $1 \mathrm{~K}$ increase of temperature ("RP10") resulted in increased flood levels in the Czech basin part and hence also at the Middle Elbe river. Already a first flood event of August 2002 in the Czech basin part (some days prior to the major event) is increased (Fig. 5). Its superposition with the Mulde flood peak, which is similar to those of the basic scenario, accelerates the rise of the overall hydrograph in Aken. Furthermore, flood duration is increased, e.g., from 6 days (basic scenario) to 8 days at a level $>3000 \mathrm{~m}^{3} \mathrm{~s}^{-1}$ which was critical regarding dike safety during the real event. With the effect of the hydrological memory, the major peak in the Czech part of the basin increased to $5560 \mathrm{~m}^{3} \mathrm{~s}^{-1}$ at Ústí n. L. $\left(4620 \mathrm{~m}^{3} \mathrm{~s}^{-1}\right.$ in the real event). At a later event stage, peaks of Wittenberg and Aken reach 4930 and $5790 \mathrm{~m}^{3} \mathrm{~s}^{-1}$ (4200 and $4480 \mathrm{~m}^{3} \mathrm{~s}^{-1}$ in the basic scenario).

2. Spatial shift of weather fields: another modification of the flood event of August 2002 derived by meteorologists was a spatial shift of a grid of boundary data of COSMO about one and two grid cells (28 and $56 \mathrm{~km}$ ) towards North, West, East and South. Accordingly, these scenarios are denoted by the symbols N1, N2, E1,..., $\mathrm{W} 2$. These shifting distances correspond to the forecast uncertainty of the COSMO boundary data (Schlüter and Schädler, 2010, for details). Among these scenarios, increased flood levels at the Middle Elbe river as compared to those of the basic scenario were identified for N1, W1 (Fig. 5) and N2. In the Mulde catchment, hydrological simulation of these scenarios led to considerably higher flood peaks than those of the COSMObased simulation of the real event (reference run). However, this increase just compensates the underestimation of the basic scenario by the reference run, which 
is presumably associated with the spatial uncertainty of COSMO. More evident are the increases of the flood peaks of $\mathrm{N} 1$ and $\mathrm{N} 2$ in the Czech basin part. Hence, also $\mathrm{N} 1$ and $\mathrm{N} 2$ flood peaks of Wittenberg increase to about $4950 \mathrm{~m}^{3} \mathrm{~s}^{-1}$ and those of Aken to $5630 \mathrm{~m}^{3} \mathrm{~s}^{-1}(\mathrm{~N} 1)$ and $5730 \mathrm{~m}^{3} \mathrm{~s}^{-1}(\mathrm{~N} 2)$. Scenario $\mathrm{W} 1$ has similar characteristics to those of the RP10, however, major flood peaks in the Czech basin part and at the Middle Elbe are considerably lower than those of the RP10 scenario.

3. Recombination of observed event elements: present paper focuses on two scenarios with very unfavorable superposition of weather sequences and hydrological catchment states, which, however, cannot be excluded.

In the first scenario, it was assumed that the extreme precipitation of 2-13 August 2002 (with a weather situation in the period 9-13 August classified as "Trough Central Europe - TCE" by Werner and Gerstengarbe, 2010) occurred once again after it had already occurred prior to 21 July 2002 (when in reality a TCE with high, but not extreme precipitation occurred). With increased moisture resulting from this scenario pre-event, the first flood event of August 2002 in the Czech basin part (due to precipitation of 6-8 August) and the Mulde flood (peak of $1870 \mathrm{~m}^{3} \mathrm{~s}^{-1}$ at site A9) are both increased (Fig. 5). Due to their superposition, extreme flow values at the Middle Elbe occur earlier than in the basic scenario, e.g., the level of $3000 \mathrm{~m}^{3} \mathrm{~s}^{-1}$ is exceeded two days earlier in Wittenberg and Aken. This flood level is still significantly exceeded by the peaks of the major event with $5600 \mathrm{~m}^{3} \mathrm{~s}^{-1}$ in Wittenberg and $6830 \mathrm{~m}^{3} \mathrm{~s}^{-1}$ in Aken.

In the second scenario, extreme precipitation of the period 6-8 May 1978 (with relatively warm temperatures up to $15^{\circ} \mathrm{C}$ in the lowland and up to $10^{\circ} \mathrm{C}$ in the LMR at these days, but else still changeable weather conditions) was combined with the extreme snow cover of 27 March 2006. Due to extremely intensified snowmelt (especially in the Mulde and Upper Elbe catchments), hydrological simulation resulted in strongly increased hydrographs as compared to those of the real flood event of April 2006. At the site A9 of the Mulde river, a flood peak of $2100 \mathrm{~m}^{3} \mathrm{~s}^{-1}$ was obtained and at the Elbe gauges Wittenberg and Aken $5560 \mathrm{~m}^{3} \mathrm{~s}^{-1}$ and $7050 \mathrm{~m}^{3} \mathrm{~s}^{-1}$ - the same order of magnitude like in above described scenario with double occurrence of $\mathrm{Au}$ gust 2002 rainfall.

\section{Conclusions}

A newly developed, stochastic-conceptual PR model could be applied successfully in the German part of the Middle Elbe river basin. In this large-scale application, the model provided robust and reliable simulations even for extreme flood events. At the same time, it is versatile enough to account for multiple flood characteristics. The model could be validated to a large extent, however, concerning flood components originating from the LMR further work based on an extended (historical) data set is recommended. Since interfaces to meteorological and HN models were included, the model is ready to be applied in operational flood management. Furthermore, the model can also be applied for other purposes, e.g., long-term continuum simulation. Due to its catchment-specific development, the model is particularly suited for the IC between the Elbe gauges Dresden and Aken. However, landscape spectrum of this catchment is similar to those of many other catchments in the Elbe basin or other areas of Central Europe. Using the top-down oriented strategy of progressive modification, recalibration or, if necessary according to diagnosis and physical interpretation, modification of the modular model structure may be realised.

Another methodical approach pursued in this paper are strategies to define large-scale, extreme flood scenarios. They can be used to analyse possible variability ranges of past (extreme) flood events with regard to enhanced process understanding, rational flood risk management with well-balanced measures and uncertainty assessment in simulation models. Mainly the question whether higher flood peaks, flood volumes or other event characteristics can make operational flood management more difficult was in the focus of present study.

The analysed set of 25 flood scenarios indeed revealed multiple characteristics of possible extreme flood hydrographs at the Middle Elbe river (and other areas in the Elbe basin). Partly the peaks and volumes of the scenario hydrographs exceed by far those of the (real) extreme flood event of August 2002. Such scenarios were not only found for the summer season, but also for spring (during snowmelt). In addition to this, scenarios show multiple spatio-temporal superposition characteristics of flood waves. Exceedance duration of critical flood levels at the Middle Elbe river (e.g., with regard to dike safety) can be several days longer than in August 2002. Furthermore, the rise of flood hydrographs can be quicker (meaning less time to prepare flood-protection measures). Finally, the role of the hydrological memory has to be emphasised. Flood-protection measures during an extreme flood event should take into account possible followup events, which may be increased due to the hydrological memory effect (e.g., filled reservoirs or polders should be unloaded as soon as possible). Altogether, the analysed scenario set shows that preparation of operational flood management at the (Middle) Elbe river is a challenge beyond the experience of the extreme flood events which occurred in the last years. A set of the most relevant flood scenarios was therefore delivered to the responsible authorities and to the partners in the joint research project in order to provide a hydrological base for $\mathrm{HN}$ simulation, dike monitoring, planning of improved flood-protection measures and preparation of operational flood management for extreme flood events at the Middle Elbe river which may occur in future. 
Acknowledgements. Present study was funded by the German Federal Ministry of Education and Research (BMBF) in the frame of the RIMAX research program. The support is gratefully appreciated.

Edited by: K. Schneider and S. Achleitner

Reviewed by: two anonymous referees

\section{References}

AquaLogic: Software documentation, available at: http://www. aqualogic.cz/Slu_by/Produkty/Aqualog/aqualog.html, last access: 5 November 2012.

Knauf, D.: Die Verechnung des Abflusses aus einer Schneedecke (Calculation of flow from a snow cover). Schriftenreihe des Deutschen Verbandes für Wasserwirtschaft und Kulturbau, 46, 95-136, Verlag Paul Parey, Hamburg, Berlin, 1980.
Kron, A., Nestmann, F., Schlüter, I., Schädler, G., Kottmeier, C., Helms, M., Mikovec, R., Ihringer, J., Musall, M., Oberle, P., Saucke, U., Bieberstein, A., Daňhelka, J., and Krejčí, J.: Operational flood management under large-scale extreme conditions, using the example of the Middle Elbe, Nat. Hazards Earth Syst. Sci., 10, 1171-1181, doi:10.5194/nhess-10-1171-2010, 2010.

Oberle, P., Musall, M., Kron, A., and Nestmann, F.: 1-D-/2-Dgekoppelte Simulation von Hochwasserabflüssen an der Mittleren Elbe (1-D-/2-D-coupled simulation of flood flow at the Middle Elbe river), Wasserwirtschaft, 7-8, 46-50, 2008.

Schlüter, I. and Schädler, G.: Sensitivity of heavy precipitation forecasts to small modifications of large-scale weather patterns for the Elbe river, J. Hydrometeorol., 11, 770-780, 2010.

Werner, P. C. and Gerstengarbe, F.-W.: Katalog der Großwetterlagen Europas (1881-2009) nach Hess, P. und Brezowski, H., 6. verbesserte und ergänzte Auflage (Catalogue of atmospheric circulation patterns of Europe (1881-2009) according to Hess and Brezowsky, 6th enhanced and expanded Edition); PIK-Report No. 119, Potsdam, 2010. 